IFN Working Paper No. 1174, 2017

\title{
Management Practices and the Quality of Primary Care
}

Jannis Angelis, Anna Häger Glenngård and Henrik Jordahl 


\title{
Management practices and the quality of primary care*
}

\author{
June 19, 2017
}

Jannis Angelis ,

a Royal Institute of Technology and Research Institute of Industrial Economics (IFN). E-mail address:

jannis.angelis@indek.kth.se

Anna Häger Glenngård ${ }^{\mathrm{b}}$,

${ }^{\mathrm{b}}$ Lund University School of Economics and Management and affiliated researcher at the Research Institute of Industrial Economics (IFN).E-mail address: anna.glenngard@fek.lu.se

Henrik Jordahlc,

${ }^{c}$ Research Institute of Industrial Economics (IFN). E-mail address: henrik.jordahl@ifn.se

\section{A B S T R A C T}

Using the World Management Survey method, we map and analyse management quality in Swedish primary care centres. On average, private providers have higher management quality than public ones. We also find that centres with a high overall social deprivation among enrolled patients tend to have higher management quality. Regarding quality of care, we find that management quality is positively associated with accessibility, but not with patient reported experience.

JEL classification: H42, I11, L23, L33

Keywords: Management quality, primary care, quality of care, accessibility, World Management Survey

\footnotetext{
* We wish to thank Ilinca Benson and Mats Brommels for helpful comments and suggestions, Hanna Thunström for excellent research assistance, and the assistants who conducted the interviews. We gratefully acknowledge financial support from the Jan Wallander and Tom Hedelius Foundation and from the IFN project Public Services in the Future.
} 


\section{Introduction}

We explore the use of management practices in primary care units, based on the World Management Survey method. Management has increasingly come into focus in health care, as the sector's growing proportion of global GDP has called for a more efficient organisation of care. Efforts to increase efficiency involve appropriate systems for organising service delivery and managing organisations. The application of management practices affects the ability to respond to the needs and expectations of patients in a cost-effective manner (Prentice et al., 2007; Bloom et al., 2015). Since there is an inherent tension between meeting objectives and providing inexpensive care, the application needs to be addressed with great consideration.

Primary care has unique characteristics that affect the implementation and use of management practices. Primary care is "that level of a health system that provides entry into the system for all needs and problems, provides person-focused (not disease-oriented) care over time, provides care for all but very uncommon or unusual conditions, and coordinates or integrates care provided elsewhere by others" (Starfield, 1998, p. 8-9). Managers in primary care face a difficult task, since the provided services are complex by definition, and physicians, nurses and other employees enjoy large degrees of autonomy in their contacts with patients (Chase and Apte, 2007; Eissens-van der Laan et al., 2016). Formal control is typically kept at a relatively low level. There is considerable uncertainty about the use of management practices to exercise formal control (De Blok et al., 2010, 2014).

Previous literature on the use of management practices in health care has focused on hospitals, which typically operate on a larger scale with organisational and functional characteristics that differ from primary care in many respects. Primary care units have a comparatively broad person focused scope and a flatter organisation with a single manager presiding over clinical staff (e.g doctors, nurses and physiotherapists) who work with a variety of patients. The management practices contained in the World Management Survey are usually grouped into three categories, focusing on monitoring of on-going operations, ensuring that set targets are met, and enabling capability development. Together these three categories provide managers with a set of comprehensive tools to keep operations efficient and effective. This may mean a quality focus, or indeed other prioritised objectives, such as reduced waiting times or costs, or improved user experience. In a health care setting, it may mean improved care quality as well as reduced administrative work needed to ensure such care is given. Regardless of sought objective, there are management practices designed to achieve it in a systematic way. The management practices under study were initially developed for manufacturing companies and later on adapted to service production. Since they amount to using private sector management models to improve public sector services, most of the practices can be included under the broad umbrella of New Public Management (cf. Lapsley, 2009), 
The management practices typically constitute key elements of comprehensive approaches to a systematic organisation of operations, such as lean or agile systems, but the practices can also be employed independently. The use of management practices, such as those found in performance systems and lean operations, has increased gradually in the health care sector and particularly in hospitals (Proudlove et al., 2008; Thomson et al., 2003; Westwood et al., 2006).

Only a few studies based on the World Management Survey have focused on the public sector, specifically on health care, education and elderly care (McConnell et al., 2013; Angelis and Jordahl, 2015; Bloom et al., 2015a, b). In health care, there is evidence to the effect that standard management practices improve operations and care at hospitals in the UK and the US (McConnell et al., 2013; Bloom et al. 2015a). To the best of our knowledge, we are the first to apply the World Management Survey method to primary care. Our purpose is to relate the scope and quality of management to different types of primary care providers and to the quality of care.

\section{Method}

We measure management quality is measured through a validated instrument, i.e. the World Management Survey method, as described in Bloom and Van Reenen (2007). By relying on a large interview-based and quantitative survey of individual management practices, the method allows for a comprehensive coverage of applied management practices. Our survey follows others using the World Management Survey method with some modifications to fit the context of primary care in Sweden (cf. Bloom et al., 2015b). Changes to the survey include removing a question on staff roles and resource allocation with units since the primary care units have very flat organisations with functionally flexible staff. The division of questions into three areas was kept (operations, targets and people).

Conceptually, the survey is based on theories of operations, performance and health care management. The survey uses semi-structured open-ended questions to measure the application of management practices. For each management practice, follow-up questions were used, typically by asking for practical examples. Potential bias is mitigated by having the interviewers interpret and score management practices without the respondents knowing how they are scored and by the interviewers not having any information about the performance of individual primary care units. The survey consists of 19 management practices, each of them scored from 1 ("worst practice") to 5 ("best practice"). An overall measure of management quality is calculated as the average over the 19 practices. We also calculate simple averages to obtain measures for the three areas operations, targets and people. 
The sample consists of Swedish primary care centres that were listed by the Swedish National Board of Health and Welfare in 2014. All of the 1197 primary care centres were contacted and 119 replied, giving a response rate of 10 per cent. The response rate is lower compared to other studies using the same method (Bloom and Van Renen 2010). Note that Statistics Sweden only achieved a response rate of 30 percent in an official survey of primary care centres in 2015 (Statistics Sweden 2015). An important reason for the low response rate is that we, unlike previous studies, have only conducted interviews with unit managers. Given the relatively small organisational size of the primary care units, they typically only have one manager, with no one in a substitute or parallel management role. This meant that unlike many organisations covered by other WMS studies where there are several relevant managers to interview, here each survey response relies on the participation of a single, typically rather busy individual. In most cases of non-response, we never got in direct contact with the unit manager. We address possible selection bias by conducting a non-response analysis with respect to variables that are observed both for respondents and non-respondents, and by comparing the responses of managers who were easy and who were hard to contact (see Appendix B). Although the non-response analysis does not indicate any serious selection problems, the results still have to be interpreted with caution due to the small sample of care centres.

The survey was conducted by five engineering graduates from the Royal Institute of Technology in Stockholm with prior work experience in operations and performance management. Initially, an email was sent to the manager of each primary care centre with information about the study and that a complementary telephone call would be made. The email was followed by telephone calls to book an interview of approximately 45 minutes. During the interview the interviewer scored each of 19 practices according to pre-determined scoring criteria (see Bloom et al., 2015b). To ensure comparability in scoring, the initial interviews were conducted with one of the interviewers listening and scoring the responses independently. The identity of the interviewer and the time of the interview were recorded in order to filter out systematic variation unrelated to the care centres.

We use regression analysis to relate management quality both to explanatory and to outcome variables at care centre level. Since the data are cross-sectional, the results should be interpreted as correlations, which may suggest rather than demonstrate causal relations.

\section{Empirical setting and data}

Sweden has a publicly funded comprehensive health care system. Responsibility for financing and organising health care rests with 21 county councils. Primary care constitutes about one fifth of total health care expenditures. There are about 1200 primary care centres, of which approximately 40 per cent are privately owned and operated. County councils control the 
establishment of providers by regulating conditions for accreditation (focusing on opening hours and clinical competencies) and payment. Any provider fulfilling the accreditation conditions may establish a practice and receive payments from the county council. Primary care providers (public and private) are paid a combination of fixed payment for their enrolled individuals (capitation), fee-for-service (mainly for visits), and performance-related payment for achieving quality targets (e.g., patient satisfaction and compliance with guidelines related to evidence-based medicine).

The average care centre in our sample has 32 employees, including eight medical doctors, and has about 8700 enrolled individuals on its client list (Table 1). The average public care centre has eight more employees (but not more doctors) and about 600 more listed persons than the average private centre. Due to political developments, public care centre are 20 years older than private centres on average. The share of public care centres is somewhat underrepresented at 32 per cent in our sample, compared with 40 per cent among all centres in Sweden (we investigate the consequences of the underrepresentation in Appendix).

Table 1. Descriptive statistics of primary care centres included in study

\begin{tabular}{lrcc}
\hline & $\begin{array}{c}\text { All care } \\
\text { centres }\end{array}$ & $\begin{array}{l}\text { Public care } \\
\text { centres }\end{array}$ & $\begin{array}{l}\text { Private care } \\
\text { centres }\end{array}$ \\
\hline No. employees & 32 & 34 & 26 \\
No. doctors & 8 & 8 & 7 \\
$\begin{array}{l}\text { Age of care centre } \\
\text { (years) }\end{array}$ & 27 & 33 & 13 \\
$\begin{array}{l}\text { No. enrolled } \\
\text { individuals }\end{array}$ & 8731 & 9013 & 8102 \\
\hline $\begin{array}{l}\text { No. care centres } \\
\text { nare }\end{array}$ & 119 & 81 & 38
\end{tabular}

Note: Table entries are mean values. Three of the private care centres are not-for-profit.

Of the unit managers, 65 per cent are nurses, with a higher share (76 per cent) among managers in public care centres compared to private ones (40 per cent). A majority of managers (76 per cent) are female, again with a higher share in in public care centres (83 compared to 61 per cent).

To describe the patient mix at each primary care centre in terms of socioeconomic deprivation among enrolled individuals we use the Care Need Index (CNI), which measures social deprivation related to seven factors, including education and unemployment (Sundquist et al., 2003). A majority of county councils use the average level of CNI of a care centre to adjust the fixed payment to expected needs among its listed individuals. 
We use two measures to describe care quality: a process measure of accessibility and a patient reported experience measure (PREM) of care quality. Accessibility is defined as the proportion of patients contacting a primary care centre who gained an appointment with a general practitioner within seven days, as measured through a national waiting time survey (SALAR 2015a). The survey is conducted during one week in October each year and we use survey results from 2014. Our measure of patient reported experience comes from an annual national patient survey. The survey is administered by mail to a random sample of patients having visited a care centre in September or October (SALAR 2015b). We use a question about the overall satisfaction with the care centre from the 2014 survey.

\section{Results}

\section{Total management quality}

For each primary care centre an overall measure of total management quality, i.e. a score from 1 ("worst practice”) to 5 ("best practice”), is calculated as the average over 19 management practices in three areas; operations, targets, and people. Total management quality varies between 2.68 and 4.79 with a mean of 3.73 ( $\mathrm{SD}=0.47$ ). The highest scores are found in the area operations with a mean of 4.20. The mean score in the area targets is 3.89. For both of those areas there are a lot of care centres with excellent management quality and only a few with a score below 3. The scores are considerable lower in the people area. The mean is 3.06 for this area; with six care centres scoring below 2 . The pattern with the highest scores in the area operations and the lowest scores in the people area corresponds to the performance of Swedish companies in previous international studies (Blooom and Van Reenen, 2010).

\section{Management quality and characteristics of care centres}

Next, we investigate differences in total management quality between primary care centres. The regression estimates, reported in table 2, contain two notable results. First, private care centres have higher management quality than public care centres. Second, management quality tends to be higher at care centres with a high level of socioeconomic deprivation among their enrolled individuals (especially so for the area targets). By contrast, total management quality seems to be uncorrelated with the age of care centres, with their number of employees, and with their number of enrolled individuals. 
Table 2. Management quality of primary care centres

\begin{tabular}{llll}
\hline & \multicolumn{1}{c}{1} & \multicolumn{1}{c}{4} \\
\hline \hline Private care & 0.174 & $0.237^{*}$ & $0.248^{*}$ \\
centre & $(0.102)$ & $(0.138)$ & $(0.136)$ \\
CNI & & $0.120^{*}$ & $0.144^{* *}$ \\
& & $(0.060)$ & $(0.062)$ \\
Age of care centre & & 0.003 & 0.004 \\
& & $(0.002)$ & $(0.002)$ \\
No. employees & & 0.005 & 0.003 \\
& & $(0.004)$ & $(0.003)$ \\
Enrolled & & -0.011 & -0.016 \\
individuals, & & $(0.015)$ & $(0.014)$ \\
thousands & & No & Yes \\
Regional controls & No & No & Yes \\
Noise controls & No & & \\
& & 0.07 & 0.32 \\
R-squared & 0.03 & 113 & 113 \\
No. observations & 119 & &
\end{tabular}

Notes: The dependent variable is total management quality. Regional controls are log of population, population growth, population density, share of population older than 64 , share of population with at least a three-year tertiary education, and median income. Noise controls are dummies for interviewer, month, and time. All regressions include an unreported constant. Standard errors clustered at the regional level are in parentheses. ***, **, * denote statistical significance at the 1,5 and 10 percent level.

\section{Management quality and quality of care}

Management practices aim at improving production efficiency. It is therefore logical to investigate if management quality is related to measures of care quality (NB: Cost data are not available at the care centre level). We find that primary care centres with higher total management quality tend to have significantly shorter waiting times. One unit on the five point scale of total management quality is associated with a 4.8 percentage point difference in the share of patients who receive an appointment within 7 days. We also find that primary care centres with higher management quality tend to receive higher scores in the PREM of care quality, although this relation is not statistically significant (see table 3). Subjective quality is, however, lower at care centres with high CNI and with a high number of enrolled individuals. 
Table 3. Management quality and quality of care

\begin{tabular}{|c|c|c|c|c|c|c|}
\hline \multirow{2}{*}{$\begin{array}{l}\text { Quality } \\
\text { measure }\end{array}$} & \multicolumn{3}{|c|}{ Accessibility (waiting time) } & \multicolumn{3}{|c|}{ Care quality (PREM) evaluation } \\
\hline & 1 & 2 & 3 & 4 & 5 & 6 \\
\hline "Total & $0.037 *$ & 0.032 & "0.048** & 1.673 & 1.418 & 1.265 \\
\hline $\begin{array}{l}\text { management } \\
\text { quality }\end{array}$ & $(0.018)$ & $(0.024)$ & $(0.023)$ & (1.110) & (1.268) & $(1.644)$ \\
\hline Private care & & -0.001 & -0.004 & & $4.279 * *$ & 3.501 \\
\hline centre & & $(0.026)$ & $(0.020)$ & & $(1.516)$ & (2.079) \\
\hline CNI & & -0.016 & -0.010 & & $-2.220^{*}$ & $-4.135 * * *$ \\
\hline & & $(0.018)$ & $(0.022)$ & & $(1.113)$ & $(1.350)$ \\
\hline Age of care & & 0.0004 & 0.0003 & & -0.008 & -0.046 \\
\hline centre & & $(0.0007)$ & $(0.0007)$ & & $(0.037)$ & $(0.045)$ \\
\hline No. & & -0.0003 & -0.0010 & & 0.057 & 0.068 \\
\hline employees & & $(0.0011)$ & $(0.0013)$ & & $(0.036)$ & $(0.041)$ \\
\hline Enrolled & & -0.004 & -0.002 & & $-0.625 * * *$ & $-0.700 * * *$ \\
\hline $\begin{array}{l}\text { individuals, } \\
\text { thousands }\end{array}$ & & $(0.004)$ & $(0.0040)$ & & $(0.126)$ & $(0.126)$ \\
\hline $\begin{array}{l}\text { Regional } \\
\text { controls }\end{array}$ & No & No & Yes & No & No & Yes \\
\hline $\begin{array}{l}\text { Noise } \\
\text { controls }\end{array}$ & No & No & Yes & No & No & Yes \\
\hline R-squared & 0.02 & 0.05 & 0.20 & 0.01 & 0.27 & 0.42 \\
\hline $\begin{array}{l}\text { No. } \\
\text { observations }\end{array}$ & 112 & 108 & 108 & 115 & 110 & 110 \\
\hline
\end{tabular}

Notes: The numbers in the table give coefficients of total management quality and other variables from regressions with share of appointments within 7 days (columns 1-3) and subjective patient evaluations (columns 4-6) as the dependent variable. Regional controls are log of population, population growth, population density, share of population older than 64, share of population with at least a three-year tertiary education, and median income. Noise controls are dummies for interviewer, month, and time. All regressions include an unreported constant. Standard errors clustered at the regional level are in parentheses. ***, **, * denote statistical significance at the 1, 5 and 10 percent level.

\section{Discussion}

This study adds to previous research on management in health care by surveying management practices in the previously neglected area of primary care. We have identified how management practices are applied to run primary care centres in Sweden, including factors which are associated with higher management quality. Overall, the results suggest a high level of management quality in Swedish primary care and are broadly in line with previous studies of hospitals in the US (McConnell et al., 2013) and in England (Bloom et al., 2015b), as well 
as in studies of nursing homes in Sweden (Angelis and Jordahl, 2015). We also find that management quality is higher at private primary care centres than at public ones.

Another notable result is that higher social deprivation among enrolled individuals is associated with higher management quality. An interesting aspect of this is that social deprivation is also associated with less satisfied patients, in line with previous studies from Sweden and the UK (Campbell et al., 2001; Kontopantelis et al., 2010; Glenngård, 2012; Glenngård and Anell, 2017). Individuals with a poor socioeconomic situation are expected to have greater needs for primary care, especially preventive measures and coordination with social services and relatives. The association between management quality and social deprivation among enrolled individuals is particularly strong for management practices in the targets area. A potential explanation is that care centres with patients who have more complex situations cannot focus on a few narrow performance measures or goals, but have to work with broad and comprehensive measures.

We also find that management quality is positively associated with accessibility. The proportion of patients who gained an appointment with a general practitioner within seven days after having contacted the care centre was higher at care centres with a high level of management quality. We find a positive but statistically insignificant correlation between management quality and patients' reported experiences of overall care quality.

The use of management practices is a delicate topic in health care given that it involves both formal and informal control mechanisms. Formal control relates to visible factors of the control system such as the information-based routines and procedures managers use in organizational activities, while informal control is grounded in an organization's employees and culture (Simons, 1995). Informal control is crucial in health care, since medical personnel have strong professional roles and are subject to diverse motivational factors. Doctors may even be referred to as double agents, having to weigh patient needs and expectations against monetary costs and other social objectives (Blomqvist, 1991). Publicly funded health care providers operate in a broader governance context where priority setting and decisions on payment are mostly made outside of the organisation. The application and consequences of management practices in health care depend on the context in which they operate including the beliefs and values held by the individuals who are subject to the control system.

Management quality was found to be highest in the area operations, which relates to administrative controls, i.e. to organization, monitoring and accountability. The freedom to implement operations management practices is constrained by the broader governance structure in which care centres operate. For example, managers are obliged to include processes for incident reporting to the Health and Social Care Inspectorate (IVO), in the management control systems. Moreover, most Swedish county councils use a small proportion of performance-based payments, forcing the providers to report their fulfilment of goals related to specific quality targets. Management practices can be (and often are) used to 
reduce the degree of staff task discretion in the pursuit of efficiency gains, with significant and possibly negative implications for the staff. In this respect, Swedish primary care constitutes a particularly interesting context. Providers are subject to national and local evidence-based guidelines and performance targets to increase their performance (Fredriksson et al., 2014; Anell and Glenngård, 2014). This has an impact on the assessment and treatment of patients as well as on the ability for managers to employ management practices that directly affect the work that individuals perform. Moreover, tasks control over clinical procedures is not necessary since the clinical component can be compartmentalised and hence detached from other operations required to manage the care unit. For instance, employing management practices to standardise routines for how patient information is handled or how staff development is organised do only indirectly affect how patients are treated. Put together, management practices may have limited consequences for the day-to-day work of staff at primary care units. As long as they follow clinical guidelines, clinical staff may still perform their assessment and treatment in an individual manner, which has been highlighted as a key issue in process- or patient-focused implementation in health care settings. (e.g. Bamford et al., 2015; Proudlove et al., 2008). This is important, since it reduces a key factor in staff disinterest in being managed through management practices, and increases potential for their application. It could have been, but is obviously not the case, that management practices are therefore ignored at primary care centres.

As in the cross-country study by Bloom et al. (2014), management quality was found to be lowest with regard to people, suggesting room for improvement in this area. The people area relates to cultural controls, which are about values, beliefs and social norms that influence employee behaviour (Simons, 1995; Malmi and Brown, 2008). One should note that management practices that seek to directly change or control the behaviour of individuals through rewards or sanctions directly related to their performance may have both positive and negative consequences. Motivation is affected by intrinsic as well as extrinsic drivers (Ryan and Deci, 2000). Intrinsic motivation is about doing something because it is personally rewarding, such as acting out of a belief about doing the right thing from a moral perspective or to feel pride in a well-done job. Management control systems may encourage but not control intrinsic motivation. Extrinsic drivers are external factors that shape behaviour such as financial rewards or fear of punishment. Management practices may be powerful when it comes to extrinsic drivers as they are easier to control. However, there is a risk that management practices may encourage extrinsic motivation to the extent that intrinsic motivation is crowed out. Health care staff often have strong professional roles and are motivated by intrinsic drivers. A strong intrinsic motivation may also be associated with a resistance towards being controlled by external factors. Hence, although the lower management quality in the area people suggests that this area has the greatest potential for improvement, caution is called for when introducing methods to directly control or change the behaviour of health care staff. 
The rather low response rate in this study calls for a cautious interpretation of the results although the non-response analysis did not indicate any serious selection problems. Moreover, our study is limited by the measures of quality available at the national level in Swedish primary care. Results from patient surveys are often uncertain due to low response rates, particularly in vulnerable groups and patient views are affected by factors not necessarily reflecting quality of services. The quality of process measures is on the other hand influenced by registration practices and linkages with end objectives or outcomes may be weak. Future studies on the relationship between management quality and the quality of care should ideally address these limitations. Finally, it is unlikely that we have taken account of all factors associated with management quality in our analysis. For example, several managers in the survey expressed that county councils organise and allocate resources in a way that affects the feasibility of applying certain management practices. This link between the purchaser's control of the provider and the provider's application of management practices remains unexplored and is recommended for further studies.

To conclude, we find a high overall level of management quality in Swedish primary care. Management quality is higher in private primary care centres and also in centres with a high overall social deprivation among enrolled patients. Management quality is positively associated with accessibility, but displays no relationship with responsiveness to patients. At system level, this implies that the expansion of private care centres has increased the average level of management quality in Swedish primary care. To providers, the findings suggest that suitable applications of management practices, especially in the area of people management, may result in higher quality of care. 


\section{References}

Anell, A. and Glenngård, AH. (2014), The use of outcome and process indicators to incentivize integrated care for frail older people: a case study of primary care services in Sweden. International Journal of Integrated Care, 14, 4.

Angelis, J. and Jordahl, H. (2015), Merciful yet effective elderly care performance management practices. Measuring Business Excellence, 19, 1, pp. 61-69.

Bamford, D., Forrester, P., Dehe, B., and Leese, R. (2015), Partial and iterative Lean implementation. International Journal of Operations \& Production Management, 35, 2, pp. 702-727.

Blomqvist, A. (1991), The doctor as double agent: Information asymmetry, health insurance, and medical care. Journal of Health Economics, 10, pp. 411-432.

Bloom, N., Lemos, R., Sadun, R. and Van Reenen, J. (2015a), Does management matter in schools? Economic Journal, 125, 584, pp. 647-674.

Bloom, N., Propper, C. and Seiler, S. (2015b), The impact of competition on management quality: Evidence from public hospitals. Review of Economic Studies, 82, 2, pp. 457-489.

Bloom N., Sadun, R. and Van Reenen, J. (2014), Does management matter in healthcare? Manuscript.

Bloom, N. and Van Reenen, J. (2007), Measuring and explaining management practices across firms and countries. Quarterly Journal of Economics, 122, 4, pp. 1351-1408.

Bloom, N. and Van Reenen, J. (2010), Why do management practices differ across firms and countries? Journal of Economic Perspectives, 24, 1, 203-224.

Campbell, J., Ramsay, LJ. and Green, J. (2001), Age, gender, socioeconomic, and ethnic differences in patients’ assessments of primary health care. Quality in Health Care, 10, 2, pp. 90-95.

Chase, R. and Apte, U. (2007), A history of research in service operations. Journal of Operations Management, 25, 2, pp. 375-386.

De Blok, C., Luijkx, K., Meijboom, B. and Schols, J. (2010), Improving long-term care provision: towards demand-based care by means of modularity. BMC Health Services Research, 10, 1, pp. 278291.

De Blok, C., Meijboom, B., Luijkx, K., Schols, J. and Schroeder, R. (2014), Interfaces in service modularity: a typology developed in modular health care provision. Journal of Operations Management, 32. 4, pp. 175-189.

Eissens-van der Laan, M., Broekhuis, M., van Offenbeek, M. and Ahaus, K. (2016), Service decomposition: a conceptual analysis of modularizing services. International Journal of Operations \& Production Management, 36, 3 pp. 308-331.

Fredriksson, M., Blomqvist, P. and Winblad, U. (2014), Recentralizing healthcare through evidencebased guidelines - striving for national equity in Sweden. BMC Health Services Research, 14, 509.

Glenngård, A. H. (2012), Is patient satisfaction in primary care dependent on structural and organizational characteristics among providers? Findings based on data from the national patient survey in Sweden. Health Economics Policy and Law, 8, pp. 1-16.

Glenngård, A. H and Anell, A. (2017), Does increased standardisation in health care mean less responsiveness towards individual patients' expectations? A register based study in Swedish primary care. Sage Open Medicine, 5, pp. 1-8.

Kontopantelis, E., Roland, M., and Reeves, D. (2010), Patient experience of access to primary care: Identification of predictors in a national patient survey. BMC Family Practice, 11, 61, pp. 1-15.

Lapsley, I. (2009), New public management: The cruelest invention of the human spirit? Abacus, 45, 1, pp. 1-21. 
Malmi, T. and Brown, D. A. (2008), Management control systems as a package - Opportunities, challenges and research directions. Management Accounting Research, 19, pp. 287-300.

McConnell, J., Lindrooth, R. and Wholey, D. (2013), Management practices and the quality of care in cardiac units. JAMA Internal Medicine, 173, 8, pp. 684-692.

Prentice, G., Burgess, S., and Propper, C. (2007), Performance-pay in the Public Sector. London: Office of Manpower Economics.

Proudlove, N., Moxham, C. and Boaden, R. (2008), Lessons for lean in healthcare from using six sigma in the NHS. Public Money and Management, 28, pp. 27-34.

Ryan, R. and Deci, E. (2000), Intrinsic and extrinsic motivations: classic definitions and new directions. Contemporary Educational Psychology, 25, pp. 54-67.

Simons R. (1995), Levers of control: how managers use innovative control systems to drive strategic renewal. Boston: Harvard Business School Press.

Starfield, B. (1998), Primary Care: Balancing Health Needs, Services and Technology. New York: Oxford University Press.

Statistics Sweden (2015), Innovationer i sjukvården 2012-2013. Stockholm: Statistics Sweden.

Sundquist, K., Malmström, M and Johansson, SE. (2003), Care Need Index, a useful tool for the distribution of primary health care resources. Journal of Epidemiology and Community Health, 57, pp. 347-352.

SALAR. (2015a), Väntetider i vården. Swedish Association of Local Authorities and Regions, http://www.vantetider.skl.se [Accessed 7 March 2015].

SALAR. (2015b), Swedish Association of Local Authorities and Regions, http://npe.skl.se [Accessed 9 March 2015].

Thompson, D., Wolf, G. and Spear, J. (2003), Driving improvement in patient care. Journal of Nursing Administration, 33, pp. 585-595.

Westwood, N., James-Moore, M. and Cooke, M. (2006), Going lean in the NHS. London: NHS Institute for Innovation and Improvement. 


\section{Appendix A: List of management practices}

\section{Operations}

\section{Layout of Care Flow}

Tests how well the care pathway is configured at the infrastructure level and whether staff pro-actively improves their own work-place organization in order to simplify their tasks.

a) Can you briefly describe the staff movements over a typical workshift?

b) How closely located are treatment rooms, waiting rooms and consumables?

c) Has the layout of the care centre or staff movements changed in recent years? How frequently do changes occur and what are they driven by?

2. Rationale for Standardisation/Care pathway management

Tests motivation behind changes to operations and what explanation was communicated.

a) Can you take me through the rationale for making operational improvements to the management of patient pathway? Can you describe a recent example?

b) What factors led to the adoption of these practices?

c) Who typically drives these changes?

\section{Continuous Improvement}

Tests process for and attitudes to continuous improvement and whether things learned are captured/documented.

a) How do problems typically get exposed and fixed?

b) Talk me through the process for a recent problem that you faced

c) How do the different staff groups get involved in this process? How are patients or relatives involved?

\section{Performance tracking}

Tests whether performance is tracked using meaningful metrics and with appropriate regularity.

a) What kind of performance indicators would you use for performance tracking?

b) How frequently are these measured? Who gets to see these data?

c) If I were to walk through your care center, could I tell how you were doing against your performance goals?

\section{User involvement/co-creation}

Explore role of patient and staff involvement in improving services.

a) How are ideas and experience captured from staff, patients, associated or partnered institutions?

b) Could you give me an example of an improvement or change of behavior that resulted from such involvement?

c) How is any such involvement conducted and managed?

6. Clearly Defined Accountability for managers

Tests whether there is formal leadership roles and accountability among managers for delivery of targets and objectives.

a) Can you tell me about the role that managers have in improving performance and achieving targets?

b) How are individual managers responsible for delivery of targets? Does this apply to cost targets as well as quality targets?

c) How do managers take on roles to deliver cost improvements? Are they selected for this 
role or do they volunteer?

\section{Targets}

\section{Performance Review}

Tests whether performance is reviewed with appropriate frequency and communicated to staff.
a) How do you review your key performance indicators (KPI)?
b) Tell me about a recent meeting reviewing your KPI's.
c) Who is involved in these meetings? Who gets to see the results?
d) What is the follow-up plan?

\section{Consequence management}

Tests whether differing levels of (personal) performance lead to different consequences (good or bad).

a) If you have agreed to a follow-up plan at a meeting, what would happen if the plans were not enacted?

b) How long is it between when a problem is identified to when it is solved? Can you give a recent example?

c) How do you deal with repeated failures in a given area?

\section{Target balance}

Test whether targets cover sufficiently broad set of metrics

a) What are the goals for your activity? What types of targets are set for the care centre?

b) Tell me about goals that are not set externally (e.g. by government, regulators).

\section{Target inter-connection}

Tests whether targets are tied to organization objectives and how well they cascade down the organization.

a) What is the motivation behind the organisation's goals?

b) How are these goals cascaded down to different staff groups or individual staff members?

c) How are your targets linked to the organization's performance and goals?

\section{Time Horizon of Targets}

Tests whether primary care centre has a ' 3 horizons' approach to planning and targets.

a) What kind of time scale are you looking at with your targets?

b) Which goals receive the most emphasis?

c) Are long and short term goals set independently?

d) Can you meet all your short-run goals but miss your long-run goals?

\section{Target Stretch}

Tests whether targets are appropriately difficult to achieve.

a) How tough are your targets? Do you feel pushed by them?

b) On average, how often would you say that you meet your targets?

c) Do all units or staff groups receive the same degree of difficulty in their targets, or do some groups get easier targets?

d) How are the targets set? Who is involved?

13. Clarity and comparability of targets

Tests how easily understandable performance targets are and whether performance is openly 
communicated.

a) If I asked your staff directly about individual targets, what would they tell me?

b) Does anyone complain that the targets are too complex or poorly selected?

c) How do people know about their own performance compared to other people's performance?

\section{People}

14. Rewarding High Performers

Tests whether good performance is rewarded proportionately.

a) How does your appraisal system work? Tell me about your most recent round.

b) Are there any non-financial or financial (bonuses) rewards for the best performers across all staff groups?

c) How does such bonus system work?

d) How does your reward system compare to that of other providers of the same service?

\section{Removing Poor Performers}

Tests whether the primary care centre is able to deal with underperformers.

a) If you had a member of staff who could not do his job, what would you do? Could you give me a recent example?

b) How long would their underperformance be tolerated?

c) Do you know of staff members who underperform deliberately, because they know that they will not be fired?

\section{Promoting High Performers}

Tests whether promotion is performance based.

a) Tell me about your promotion system?

b) What about poor performers? What happens with them? Are there any examples you can think of?

c) How would you identify and develop your star performers?

d) Are better performers likely to promote faster or are promotions given on the basis of tenure/seniority?

\section{Managing talent}

Tests what emphasis is put on talent management.

a) How do managers show that attracting and developing talent is a top priority?

b) Do staff get any rewards for bringing in and keeping talented people in the organization?

\section{Retaining talent}

Tests whether the care centre actively tries to keep talented people.

a) If you had a top performer who wanted to leave, what would your organization do?

b) Could you give me an example of a star performer being persuaded to stay after wanting to leave?

c) Could you give me an example of a star performer who left the organization without anyone trying to keep them?

\section{Attracting talent}

Tests the strength of the employee value proposition.

a) What makes it distinctive to work in your organization, as opposed to similar primary care centres? 
b) If I were a top performer and you wanted to persuade me to work in your organization, how would you do this?

c) What don't people like about working in your organization?

\section{Scoring}

The scoring follows Bloom et al. (2015b). Each practice is given a score between 1 and 5 . As an example, the following scoring grid is used for practice 15, Removing poor performers: Score 1: Poor performers are rarely removed from their positions.

Score 3: Suspected poor performers stay in a position for more than a year before action is taken.

Score 5: We move poor performers out of the care centre or to less critical roles as soon as weakness is identified. 


\section{Appendix B: Non-response analysis}

Table A1 compares primary care centres in Sweden and in our sample with respect to ownership, region, enrolment, waiting times and patient reported experience. The main difference is that the share of private care centres is 9 percentage points lower in our sample than in Sweden. There is also a difference of 2 percentage points in the share of patients with a waiting time below 7 days, which is statistically significant at the 7 percent significance level. However, if we apply weights that are inversely proportional to the inclusion likelihood of a private and a public care centre, the average management quality changes only marginally.

Table B1. Primary care centres in Sweden and in our sample

\begin{tabular}{lcc}
\hline & $\begin{array}{l}\text { Primary } \\
\text { care centres } \\
\text { in Sweden }\end{array}$ & $\begin{array}{l}\text { Primary } \\
\text { care centres } \\
\text { in our } \\
\text { sample }\end{array}$ \\
\hline Private care centre & $40.5 \%$ & $31.9 \%$ \\
Three biggest regions & $48.0 \%$ & $44.5 \%$ \\
$\begin{array}{l}\text { No. Enrolled } \\
\text { individuals } \\
\text { Waiting time }\end{array}$ & 8140 & 8731 \\
$\begin{array}{l}\text { Patient reported } \\
\text { experience }\end{array}$ & $92.0 \%$ & $89.9 \%$ \\
\hline
\end{tabular}

Note: Table entries are sample shares and mean values.

In the same manner, we have investigated the sensitivity of the regressions in Tables 2 and 3 by using weights that are inversely proportional to the inclusion likelihood of a private and a public care centre. Overall the differences are minor.

We have also investigated the relationship between total management quality and the number of phone calls required to conduct an interview. The logic is that managers at care centers with high management quality could be more prone to take part in the survey, which would lead us to overestimate overall management quality. However, the relationship between total management quality and number of phone calls is far from statistically significant. Since the relationship is positive, the risk is, if anything, to underestimate overall management quality. 